\title{
Aspects of the political economy of development and synthetic biology
}

\author{
Rachel Wellhausen · Gautam Mukunda
}

Received: 15 May 2009/Revised: 12 June 2009/Accepted: 1 July 2009

(C) The Author(s) 2009. This article is published with open access at Springerlink.com

\begin{abstract}
What implications might synthetic biology's potential as a wholly new method of production have for the world economy, particularly developing countries? Theories of political economy predict that synthetic biology can shift terms of trade and displace producers in developing countries. Governments, however, retain the ability to mitigate negative changes through social safety nets and to foster adaptation to some changes through research, education and investment. We consider the effects the synthetic production of otherwise naturally derived molecules are likely to have on trade and investment, particularly in developing countries. Both rubber in Malaysia and indigo dyes in India provide historical examples of natural molecules that faced market dislocations from synthetic competitors. Natural rubber was able to maintain significant market share, while natural indigo vanished from world markets. These cases demonstrate the two extremes of the impact synthetic biology might have on naturally derived products. If developing countries can cushion the pain of technological changes by providing producers support as they retool or exit, the harmful effects of synthetic biology can be mitigated while its benefits can still be captured.
\end{abstract}

Keywords Synthetic biology - Political economy · Developing countries $\cdot$ Rubber $\cdot$ Indigo

\footnotetext{
R. Wellhausen $(\square) \cdot$ G. Mukunda

Department of Political Science and Program on Emerging

Technologies, Massachusetts Institute of Technology,

Cambridge, USA

e-mail: rwellhau@mit.edu

G. Mukunda

e-mail: mukunda@mit.edu
}

\section{Introduction}

Synthetic biology, defined here as the attempt to create modular and standardized biological parts that can be assembled into more complex systems with useful applications, is a rapidly growing field producing a first wave of commercial applications. Biological systems producing anti-malarials, fabrics, flavors, and biofuels have received scientific and popular attention. While synthetic biologists may eventually be able to construct entirely novel biological systems, initial commercial applications use biological systems to replicate naturally occurring molecules. Synthesized anti-malarials substitute for naturally occurring sources of artemisinin, traditionally derived from Artemisia annua. Researchers are exploring how to economically synthesize spider silk, the strongest naturally occurring fiber. Flavor firms have long used synthetic production to produce flavors like strawberry, which are too expensive to naturally derive en masse; new synthetic production techniques will facilitate more opportunities to substitute lab-produced for naturally derived flavors. And applications of synthetic biology to biofuels can shift demand from corn toward other cellulosic inputs such as switchgrass. While estimating the impacts of these types of process and product substitutions is inherently speculative, this paper attempts to demonstrate some effects synthetic biology could have on traditional producers of molecules with newly synthesizable substitutes, particularly those within developing countries.

A move from naturally-sourced to laboratory-sourced molecules follows a tradition of major technological advances that have displaced former methods of production. These include the advent of interchangeable parts manufacture of firearms, the employment of the cotton gin in the American South, Taylorist workplace organization, 
and Fordist assembly line production, and the rise of plastics as cheap inputs for consumer goods production (Smith and Chandler 1977; Hounshell and Chandler 1984; Aitken 1985). Like these past advances in production methods, synthetic biology-facilitated production may allow the manufacture of mass quantities at costs that are orders of magnitude lower than incurred through natural derivation. While the cheap mass production of naturally occurring molecules has positive implications for productivity, it will also create losers among firms and laborers employed in current methods of production. The task of market regulators is to manage the tradeoff between the benefits new technologies provide for consumers and the costs they impose on existing producers. Existing producers, as a concentrated interest group, often wield significant political power and can obtain regulatory or government support to cushion the impact of new competition. In developing countries, however, governments often have limited resources available to limit competition from new technologies or compensate losers.

The first wave of synthetic biology's commercial applications has the potential to create a complex set of winners and losers in developing countries. Civil society organizations like the ETC Group have raised awareness of the ethical and developmental implications of synthetically derived inputs on laborers (ETC Group 2007, 2008). For example, synthetic biologists are in the process of scaling up production of artemisinic acid, the key input for antimalarial drugs. Substituting this cheap, mass-produced alternative for natural sources of artemisinin improves poor laborers' access to anti-malarials while simultaneously displacing employment. Indeed, though multinational firms committed to existing technologies are generally headquartered in industrialized countries, farmers and laborers responsible for the harvesting of molecules from natural sources are often located in developing countries that have comparative advantages in these activities. Even when new technologies provide an unambiguously positive outcome for public health, the resulting economic dislocations can disproportionately place new burdens on developing country producers and their governments.

While synthetic biology in particular has not yet forced adaptations upon developing country producers, other recent and historical tensions between natural and synthetic producers provide some parallels upon which we can draw to consider synthetic biology's potential impacts. For example, improved rapeseed oil has come to replace natural oils (like palm and coconut) in many food products, and many synthesized medicines have replaced previously naturally derived active principles. But predictions that synthetic vanilla substitutes will displace natural vanilla producers in Madagascar and elsewhere have not yet been realized (Busch et al. 1991; Lehrman 1992). In this paper we focus on two historical cases that illustrate two extremes of the effects of synthetic production on developing country producers of natural products. In the case of synthetic rubber, natural rubber producers were able to retain some market share and adapt; in the case of indigo dyes, rural Indian farmers lost their market share and their livelihood, leading to mass impoverishment. Both of these cases highlight the role of government in facilitating producers' adaptation and, indeed, the role of chance and outside factors in determining if a synthetic substitute succeeds and whether a natural product retains market share. By illustrating two extremes of synthetic production's impact on developing countries, these cases provide some parameters by which analysts can make judgments about the pressures synthetic biology might put on developing country-dominated markets. Using two cases means that we can demonstrate only a few potential implications of new synthetic modes of production and that any conclusions based on these historical processes must be tentative. Nevertheless, these cases show that, while synthetic biology's potential implications cover a broad range, policy responses to technological dislocations can sometimes have significant positive effects.

The range of potential synthetic biology applications in natural and non-natural biological systems is unknowably vast, so much so as to make it fruitless for this paper to speculate on impacts to particular industries. Instead, this article's main focus is to discuss the conflicts likely to arise should synthetic biology prove capable of scaling up as well as some strategies adversely impacted developing countries might use to adapt.

\section{Effects of synthetic biology on developing countries}

Synthetic biology is likely to have significant effects on the cost benefit analyses of a variety of actors in the international economy. Basic economic insights can shed light on what those effects are likely to be. First, competitive synthetic production of molecules will significantly lower production costs. Production that takes advantage of economies of scale can reduce unit costs, sourcing closer to home can reduce transportation expenses, and reducing demand for developing country exports can lower exposure to political risks. Lower cost molecules can also lower the costs of complementary products that serve as inputs in production processes. Technological improvements change the cost-benefit analysis of a variety of producers along the supply chain, and some of these producers will have more difficultly adapting old modes of production than others. The inability to adjust can lower existing firms' profits, as old technologies obsolesce and new technologies gain market share. If these profits are lowered to unsustainable levels, firms will be priced out of the market. 
But political considerations interact with lowered costs of production to change producers' cost benefit analyses. Economic and political distortions to producer costs and benefits throw into question whether, how, and when new technologies replace old technologies (Olson 1971; Oye 1992). For example, industrial organization, or the spread of ownership in an industry, can give old technologies staying power. If the number of owners in an industry is low, firms can better organize around their collective interest in protecting old technologies. If firms' collective action results in legislation protecting old technologies, new firms are less able to enter the market and introduce the new technologies. If an industry is monopolistic and is not hindered by anti-trust law, the single owner can use temporary price-cutting to limit entry of new players. The nature of buyers, too, can influence the pace and scope of technology diffusion. For example, if the government is a monopsonist, political interest groups can influence whether a government throws its purchasing power behind a new technology or not. On the other hand, freer markets in which many competitors of relatively equal size compete for many buyers allow the mechanisms of entry and exit to push old technologies out and replace them with new ones.

The salience of a particular market to voters or, in a nondemocratic state, to those with the ability to mobilize political opposition, can also cause sensitive politicians to change the incentive structure or legal ability for firms to enter or exit an industry. Uncompetitive technologies and processes plague former Soviet industrial powerhouses, for example, but the social prominence of these industries has inspired a variety of political strategies to slowly restructure while maintaining employment and stalling firm entry (Roland 2000). While the new ability to synthetically produce naturally derivable molecules can lower production costs, a variety of other institutional structures, market characteristics, and political considerations can do much to shape the diffusion of such a technology.

A central concern among civil society groups, however, is that the outcomes of political debates will be dominated by the advanced industrial countries that are responsible for developing, marketing, and commercializing synthetic biology but have little incentive to take into account the social costs of technological change for developing countries. In short, advanced industrialized countries will have little interest in subsidizing the losers from the advent of synthetic inputs, because those losers will generally be located in developing countries. The ETC Group makes this argument most forcefully:

Synthetic biology is...likely to have massive downstream impacts on marginalized peoples if it is adopted.... Microbes programmed to make industrial substances could potentially destabilize South economies and employment. Synthetic biology... will dramatically transform the demand for agricultural raw materials required by food processors. (ETC Group 2007)

The ethical problems here may be intractable. For example, the advent of synthetically derived goods that increase the standard of living in developing countries both benefits and displaces laborers involved in their natural production. Developing country governments are left with the task of redistributing resources to cushion these newly impoverished laborers despite the decrease in their tax base. Where one falls on this tradeoff between livelihood and quality of life likely depends on where one sits. But leaving the ethical question aside, synthetic biology need not always create such stark tradeoffs. The next two sections lay out long and shorter-term factors that can allow synthetic biology technologies to work in developing countries' favor.

\section{Long-term mitigating factors}

The commercialization of synthetic biology gives rise to several long-term factors that improve the chances of developing countries successfully adapting their economies and maintaining employment. Though some economic dislocations may be unavoidable, governments have ways to create replacement revenue streams and promote employment within the context of synthetic biology. For example, synthetic biology research is increasingly international, and many in the discipline consciously steer it toward incorporating standardization, accessibility, and democratic principles (Mukunda and Mohr 2007; Mukunda et al. 2009). Even if these countries lose out from synthetic biology applications in certain areas, they may gain from their own domestic applications of synthetic biology in others. This possibility is not too far-fetched: the last two annual meetings of synthetic biologists have taken place in Switzerland and Hong Kong, with hundreds of attendees and presenters from around the world. The International Genetically Engineered Machines (iGEM) competition involves teams of university undergraduates and sometimes high school students from around the world, each designing and producing a biological system. The components of these systems draw on registries of biological parts which are made to standards emerging from the community of scholars and of increasing quality and availability. The subtext of the competition is that synthetic biology is accessible, even to undergraduates and high school students, and engineering-inspired standardizations in the discipline make the construction and implementation of biological systems possible for a wide range of people. The last two teams to win the iGEM competition were from China and Slovenia. 
Even without the widespread use of synthetic biology in developing countries, the impacts of synthetic biology will likely be more complex than only displacing certain groups of agricultural laborers. Exports from oil-rich countries may be threatened if and when biofuels production is able to replace oil-derived fuels. However, oil importing developing countries that export potential biofuel feedstocks may see rising demand and prices for these exports if large-scale biofuels production becomes economically feasible due to advances in synthetic biology. For example, switchgrass, sugar cane, and other agricultural products have been tried or proposed as potential inputs for synthetic biology-based biofuels production processes; all of these are agricultural products in which developing countries are likely to have a comparative advantage. One dramatic geopolitical change associated with the decline of oil demand would be a massive decrease in the economic and political clout of oil-rich OPEC countries in favor of a more diffuse resurgence of the international importance of agriculturally intense economies. However, the conversion of food crops to fuel production has the potential to significantly increase the cost of staple food products and exacerbate concerns about continuing food crises (The World Bank 2009). Yet this impact may be minimized should further improvements in synthetic biology allow for increased efficiency in converting biomass into fuel and the utilization of non-food feedstocks (Rajagopal and Zilberman 2007).

Finally, the fundamental uncertainty and unpredictability as to how or how well synthetically-derived biological systems can replace goods and services, or provide wholly new goods and services, makes any prediction of synthetic biology's long-term impact on the international economy necessarily highly uncertain. The enterprise could fail to spread, and this first wave of applications may never threaten developing countries' economies through massive changes in international markets. But even if synthetic biology fundamentally changes production processes in a "biological industrial revolution," there are still potential opportunities for developing countries to themselves profit from new technologies.

\section{Shorter-term strategies}

How can those countries vulnerable to the first wave of synthetic biology applications adjust in the short to medium term? The international civil society movement, including the ETC Group and others, provides one entry point. Synthetic biology as an industrial approach benefits from the fact that its implications overlap with a host of issues: social justice concerns, environmental protection, biodiversity, and national security among others. This maze of issues touched by synthetic biology has already mobilized a variety of non-governmental organizations (NGOs) in both developing and industrialized countries (McCray et al. 2008). At their third and fourth international meetings the synthetic biology community hosted discussions that included a number of such organizations. The NGO community's protest against their perceived exclusion from the second international meeting boosted scientists' incentives to include and consider NGO views as an integral part of their work (McCray et al. 2008). NGO leaders recognize that their relationships with some leading synthetic biologists are relatively unique among scientific communities (Wellhausen 2008). While the relationships between scientists and activists are currently driven more by conflict than agreement, direct NGO interactions with synthetic biologists indicate that scientists themselves are aware of their technology's social impacts. NGO activity, combined with scientific awareness, can help cushion the impact of new synthetic processes on natural producers in developing countries. As laboratory science moves into commercialization, however, it is unclear how well existing scientist-NGO ties will transfer, especially when the goals of NGOs are so varied.

The extent of employment displacement in developing countries could also be mitigated by consumer activism that protects naturally derived products' market share. The fair trade, anti-GMO, and organic movements are examples of activism making upstream production processes relevant to consumer choice, particularly in the United States and European Union (Vig and Faure 2004). Indeed, the distinction between synthetic biology and GM processes might be too fine for the public, or regulators, to distinguish between, making them both subject to the same norms and guidelines. Environmental sustainability, human health, and labor issues behind these consumer movements also have analogues in critiques of synthetic biology. For example, controversies over what cellulosic inputs are necessary for biofuels production, and their impacts on sustainable agriculture, drive debates among US policymakers and have created social backlash over the use of corn in ethanol production, including NGOs and scientists (Union of Concerned Scientists 2007). Concern over the risks of environmental release of engineered microbes has spurred technical interest in designing systems incapable of life outside the lab and policy concern over how such safeguards could be sufficiently proven (Synthetic Biology 4.0 Panelists 2008). Labor issues play out as well in critiques of synthetic biology, as critics see synthetic production of naturally derived molecules as not only undermining fair wages and labor standards but employment altogether in developing countries. While several factors point toward the possibility of a consumer movement developing around synthetic biology-origin products, even a small market share for synthetic products could 
displace developing country workers. Therefore, there remains an important role for developing countries to play in facilitating adaptation if producers are displaced by new technologies.

Whether synthetic biology fizzles out or causes a revolution, whether developing countries are able to profit from synthetic biology or simply find their exports displaced, and whether policies to protect market share could work or not, there is still another reason for developing countries to take solace despite the perceived threat of synthetically derived substitutes. Adaptation to new technologies has been shown not only to be possible but also to be a key component of technological progress in the last two hundred years. Successful adaptation to new technologies requires national governments to reconsider their areas of comparative advantage, pursue new types of industrial policies, and create environments conducive to entrepreneurial behavior (Rodrik 2007). But often, new technologies do not wholly replace demand for naturally derived inputs, even in the absence of a concerted consumer movement. This allows developing country governments to facilitate industrial restructuring and redistribute to economic losers in the context of a remaining, though reduced, market for natural products. When natural products lose their market presence, however, governments must act faster to cushion producers' fall and facilitate industrial restructuring. Developing countries, however, do not always have the capacity to facilitate effective research or industrial restructuring; in these cases, the social impact of technological change is more severe. The following section illustrates both successful and unsuccessful governmentfacilitated adaptation, using the cases of Malaysian rubber and Indian indigo dyes.

\section{Rubber and indigo}

Synthetic rubber and Malaysia

Rubber is crucial to modern industrial society, a product used in everything from tires to seals. Natural rubber is derived from rubber trees (hevea brasiliensis, a member of the Euphorbiaceae family), which are generally grown on plantations in tropical climates. The size of the rubber market as well as climatic advantages made natural rubber one of the primary exports of many colonies and developing countries before World War II, with it playing a particularly important role in Malaysia. When the United States entered World War II, however, it was cut off from world supplies of natural rubber as major producers like Malaysia were under Japanese occupation. This posed a major challenge to the American war effort; the government responded by launching crash programs to create a domestic rubber industry. This new industry used petroleum as a raw material to create synthetic substitutes for natural rubber. After the war ended, the American government privatized the synthetic rubber firms, leading to the creation of an international synthetic rubber industry which began to compete with natural rubber (Herbert and Bisio 1985).

Starting in 1948, synthetic rubber steadily increased its share of world industrial rubber usage. Quality improvements brought about by advanced technology allowed synthetic rubber to serve as a substitute for more and more natural rubber applications. But it took until 1959 for chemists to discover how to make synthetic rubber with mechanical properties equal to those of natural rubber, although synthetic rubber continued to improve until they surpassed the performance of natural rubber for most industrial uses. Improved synthetic rubber allowed the manufacture of tires, for example, with significantly better performance than had previously been thought possible (McHale 1964). By 1969 more than $60 \%$ of worldwide industrial rubber was synthetically produced (See Fig. 1) (Lim 1973).

Nevertheless, synthetic rubber has not eliminated the production of natural rubber. In fact, even as natural rubber's share of total world production dropped the total production of natural rubber increased (McHale 1965). World demand for rubber skyrocketed after World War II because of increasing industrialization as well as the spread of automobiles and the corresponding need for tires (Coates 1987). In 1957, natural rubber remained the "mainstay" of the Malaysian economy, and Malaysian rubber was the single most valuable export crop produced by any British colony (Bauer 1957). But competition from synthetic rubber forced natural rubber producers to make productivity improvements that ranged from planting and tapping new fields of rubber plants to developing chemical treatments that significantly increased the yield from

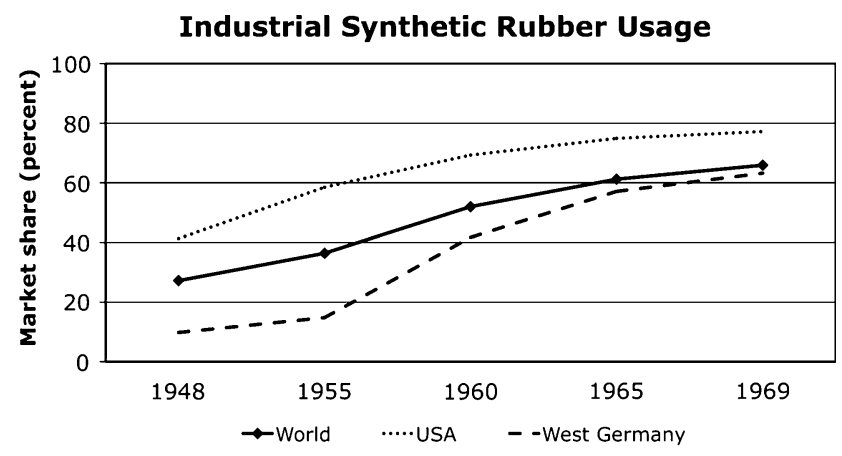

Fig. 1 Synthetic rubber accounted for an increasing share of the rubber market during the immediate post-World War II period, leveling at around $60 \%$ by 1969. Source: Lim (1973) 
individual rubber plants (McHale 1965; Rudner 1981). In achieving these productivity gains, Malaysian natural rubber producers received significant assistance from the Malaysian government. For example, Malaysia imposed an export tax on rubber and used the proceeds to fund research on improving farm productivity, planting new cloned trees with superior yields and adding "new fertilizers, tapping procedures, and chemical stimulants." These improvements were so effective that Malaysian natural rubber production doubled during the early 1960s (McHale 1965). By 1973 yields had increased to $1,800-3,000 \mathrm{~kg}$ per hectare, up from $400-500 \mathrm{~kg}$ of per hectare after World War II. As late as 1976, natural rubber accounted for a quarter of Malaysia's total export earnings (Rudner 1981).

Fluctuating oil prices, the main ingredient in synthetic rubber, have also helped natural rubber to maintain its market share. As the price of oil increases, natural rubber becomes a more and more attractive substitute. The cushion provided to price competitiveness during the 1970s oil shocks, for example, greatly benefited the Malaysian economy and provided the government with revenue streams that it continued to direct toward research and development (see Fig. 2) (Rudner 1981). Cushions provided by high natural rubber prices, too, have given prior natural rubber exporters like Brazil, Mexico, and India the time and space to restructure toward the manufacture of synthetics. Natural rubber has been able to maintain its position as a highly profitable crop despite the substantial resources of the synthetic rubber industry, and low- and middle-income countries that used to produce natural rubber have been able to successfully capture at least some of the profits from synthetic rubber. Retained market share as well as successful adaptation in the face of a synthetic substitute bodes well for countries affected by synthetic

\section{World Rubber Price}

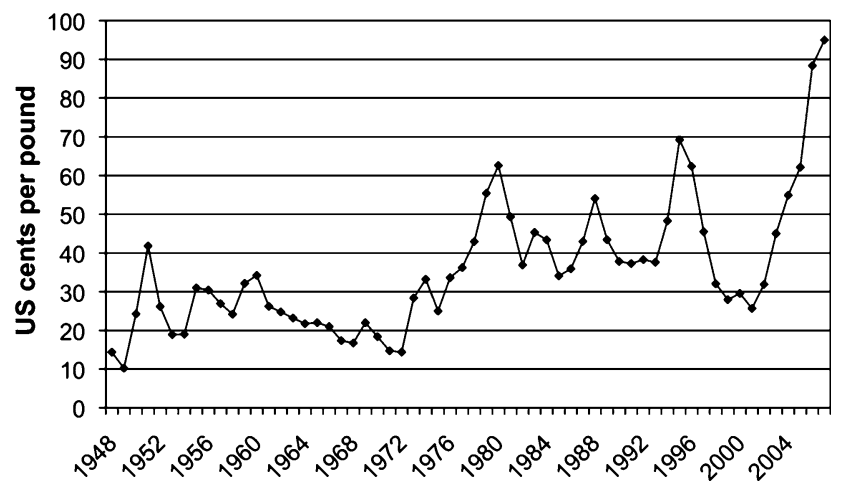

Fig. 2 The world rubber price responds in part to the price of oil, as shown by the price increase throughout the 1970s. Source: International Monetary Fund (IMF), average yearly price on Malaysian, Singaporean, and Thai indices 1948-2007 biology, particularly if the competitiveness of natural products can benefit from research and development.

Indigo and India

Indigo (indigofera tinctoria) is a perennial shrub of the family Leguminosae. Although production of indigo in India predates British rule, encouragement from the British East India Company helped it emerge as a major industry in the late eighteenth century (Kumar 2001). Indian indigo exports continued to grow throughout the nineteenth century; by the 1890 s India cultivated 574,000 ha of indigo and exported mass quantities all over the world (MartinLeake 1975; Headrick 1996; ETC Group 2005).

The German chemist Karl Heumann first chemically synthesized indigo dye in 1890 , and by 1897 , Germany was engaged in large-scale synthetic indigo production. Commercial synthesis of indigo had a massive effect on the world market as the price of indigo dropped by $50 \%$ between 1899 and 1903. Natural indigo, unlike natural rubber, had little or no qualitative advantage over its synthetic rival even when chemical synthesis was first developed. This forced existing Indian producers to compete purely on price. In fact, as the synthetic process advanced artificial indigo was soon perceived to have a quality advantage because its greater uniformity allowed lessskilled dyers to use it (Kumar 2001).

The British colonial government in India responded to the threat from synthetic indigo once the increasing displacement of rural indigo producers began to cause large increases in unemployment. British rulers also got confirmation from a London-based expert that natural indigo had no qualitative advantages over the synthetic substitute (Kumar 2001). The colonial government subsequently supported indigo research and development by matching planters' funds and giving considerable financial support to a scientific research program meant to improve the yield of indigo plantations. Although these efforts led to substantial improvements in both quality and productivity, they failed to allow Indian natural indigo to compete with its German synthetic substitute. The failure of Indian research and development was compounded by the vastly greater financial and scientific resources German chemical companies were devoting to indigo production (Martin-Leake 1975; Kumar 2001).

The decline in India's comparative advantage in indigo production became so severe that for every year save one from 1897 to 1914 the sale price of indigo was lower than the planters' unit cost of production. Indigo acreage in the Indian state of Bihar dropped from a peak of 135,769 acres in $1894-1895$ to only 404 by $1934-1935$ (Martin-Leake 1975; Kumar 2001). 
India's rural famers responded to this unpromising scenario by switching from indigo to sugar cane production. India today is the second largest producer of sugar in the world. But as the British colonial government provided a poor social safety net for farmers, and little support for the countryside's switchover to this new cash crop, the synthetic indigo disruption massively impoverished rural India. Some argue that the economic effects of this virtual elimination of the region's primary cash crop would continue to cripple it decades later (Kumar 2001; ETC Group 2005).

In marked contrast to natural rubber growers, natural indigo maintained no advantage over the new synthetics and Indian producers lost their market share. If governments assist producers as they shift to new markets, competitive advantage can be restored in the long term while poverty is mitigated in the short term. Though India eventually developed a comparative advantage in sugar production, there was little short-term support for farmers undergoing the transition to the new cash crop. If some of developing countries' products today, like indigo in the nineteenth century, are unable to maintain advantages over synthetic substitutes, active support will be necessary to cushion producers' transition.

\section{Unpredictable impacts of disruptive technologies}

Clayton Christensen's work on innovation suggests that new technologies may have the largest impact on established industry structures when they are "disruptive" innovations. Christensen describes disruptive innovations as those which are inferior on qualities important to the most profitable customers in a market but superior on attributes like price or convenience that are preferred by other, less important, customers. Such innovations are often extraordinarily difficult for the dominant players in an industry to utilize (Christensen 2003). One of Christensen's identified types of disruptive innovations, a "newmarket" disruption, occurs when a new product is adopted by users who never realized that they had a need for such a product in the first place, but begin to use it when its low cost or high convenience creates entirely new uses for an innovation. Transistors, for example, first had a major commercial impact when Sony introduced the transistor radio. Transistor radios were vastly inferior to vacuum tube radios in terms of sound quality, but they were less expensive and, unlike tube-based radios, they were portable. The combination created an entirely new market, one that the vacuum-tube radio manufacturers were unable to exploit (Christensen and Raynor 2003).

Synthetic production can be both disruptive and nondisruptive. Indigo synthesis, for example, was not a disruptive technology; it was simply superior to its natural rival on all measures of performance. Disruptive innovations can be exceptionally difficult to identify, especially prospectively, and the disruptiveness of a technology is determined by the characteristics of the dominant companies in a market (Mukunda 2010). Synthetic rubber's combination of lower quality, lower cost, and greater accessibility during wartime, however, allows us to plausibly analyze it as one and suggest that some forms of new chemical synthesis will be disruptive technologies instead of radically transformative ones. If this turns out to be the case, then they may have much larger impacts than is a priori predictable from the standpoint of both consumers, who will be offered new and unexpected choices, and that of producers, who will find themselves competing against difficult-to-counter rivals. Synthetic rubber, for example, helped spur the worldwide growth of the automotive industry by lowering the cost and improving the performance of rubber tires. Disruptions also often take some time to capture an entire market, however, suggesting that disrupted industries may not be superseded as rapidly as Indian indigo farmers were.

New-market disruptive innovations stemming from synthetic biology are most likely to occur when biological materials offering exotic capabilities that are currently very expensive to obtain suddenly become much less expensive to synthesize. Potential customers who currently do not even consider such materials due to their prohibitive cost would begin to use them, first in existing products, then in entirely new ones that take advantage of the sudden relaxation of technological and financial constraints. Such new-market disruptions can provide consumers with highly valuable new products and capabilities; they can also enable the creation of vast industries that can eclipse in scope the one they originally disrupted. Just as decreases in the cost and improvements in the performance of synthetic rubber aided increased industrialization and the spread of the automobile, synthetic biology-derived new-market disruptions may have ripple effects that spread through an entire economy, increasing productivity in entirely unanticipated areas. Such new products and industries may be where the largest long-term benefits from new technologies are eventually generated-as was the case with the transistor-but their inherent unpredictability means that they are rarely, if ever, taken into account in prospective assessments of new technologies.

Although disruptive innovations can have dramatic effects on industry structures, their very nature provides them substantial protection against regulatory and political strategies meant to limit their use. They succeed in part because established actors are almost universally unaware of their potential impact; so these same actors are unlikely to be motivated to use their political influence to block the innovations until it is too late for any such attempt to succeed. 


\section{Conclusion}

Industrial and commercial applications of synthetic biology have the potential to change demand for existing products in a number of industries. With its ability to facilitate low cost, large-scale production, and at times unpredictable market changes, synthetic biology may reduce demand for some naturally derived products and, in the process, affect the current terms of trade for various countries. Synthetic biology is likely to cause economic pain in these countries as firms adjust to changing demand and before governments can provide social safety nets to mitigate dislocations.

The potential efficiency and human development benefits of synthetic biology applications, combined with the dominant bargaining position of the industrialized country purveyors of new production processes, will lead to the diffusion of synthetic biology applications so long as they succeed technically. While developing country producers have vested interests in slowing and limiting the diffusion of new technologies, their ability to achieve these outcomes correlates with political power, both with their own governments and with trade and investment partners. As the innovation literature suggests, most of the largest effects of new technologies are likely to be unforeseen and unforeseeable as entrepreneurs find unexpected applications for the new technologies. Thus developing country producers interested in slowing technological diffusion cannot always organize ex ante, leaving new technologies more space to lock-in before political conflicts arise. Even developing country governments balance concessions to producers against the fact that new products and market disruptions are positive from a consumer perspective.

Yet technological diffusion does pressure governments to redistribute toward displaced workers and develop new employment opportunities. Scholars have shown that robust welfare states, providing social transfers to the economically disadvantaged, can and do coexist with open economies (cf. Polanyi 1944, Swank 2002). However, welfare states and social protection policies are comparatively weak in developing countries. The potential for minimizing economic dislocation through social support, therefore, depends on state capacities that are only indirectly related to a country's exposure to synthetic substitutes. The case of synthetic rubber provides one positive example of a developing country government able to support research and retooling to improve natural rubber producers' competitive standings. But, especially if synthetic products are perfect substitutes for natural ones, as was the case for indigo, the failure of targeted government intervention can lead to widespread poverty as producers adapt, as occurred in among Indian indigo producers.
Despite these caveats, there are reasons to temper the direst of predictions about the effects of synthetic biology on developing country economies. Technologically driven market disruptions make available new product varieties at lower costs, unambiguously benefiting consumers regardless of their exposure to dislocation as producers. Despite the potential imbalance of political and economic bargaining power between developing countries and the firms in industrialized countries, producing these substitutes, it is difficult to predict ex ante which firms will succeed. The unpredictability of innovation creates disruptions not only among existing producers but also among firms attempting to capture the rents of innovations. Given NGO interest in synthetic biology, the modularized and accessible format of synthetic biology technology, and the general upswing in consumer support for natural products and conservation, it seems likely that countries negatively impacted by synthetic biology-derived products will have opportunities to retain market share and even benefit from access to new technologies. Nevertheless, after a market dislocation, domestic governments still play a crucial role in facilitating the efficient reallocation of resources and workers so as to play to new areas of competitive advantage.

Acknowledgments We thank Kenneth Oye of the MIT Department of Political Science and Engineering Systems Division, participants in the MIT Program on Emerging Technologies, and Markus Schmidt and the anonymous reviewers for Systems and Synthetic Biology for their insights, advice, and helpful commentary. We also thank participants at Synthetic Biology 3.0, Synthetic Biology 4.0, and members of the Synthetic Biology Engineering Research Center (SynBERC) for their interest in this topic and their feedback. Funding for this work came from MIT's National Science Foundation Integrative Graduate Education and Research Traineeship (IGERT) and the Synthetic Biology Engineering Research Center (SynBERC). All errors are our own.

Open Access This article is distributed under the terms of the Creative Commons Attribution Noncommercial License which permits any noncommercial use, distribution, and reproduction in any medium, provided the original author(s) and source are credited.

\section{References}

Aitken HGJ (1985) Scientific management in action: Taylorism at Watertown Arsenal, 1908-1915. Princeton University Press, Princeton

Bauer PT (1957) Malayan rubber policy. Polit Sci Q 72(1):83-99

Busch L, Lacy WB et al (1991) Plants, power, and profit: social, economic, and ethical consequences of the new biotechnologies. B. Blackwell, Cambridge

Christensen CM (2003) The innovator's dilemma. Harper Business Essentials, New York

Christensen CM, Raynor ME (2003) The innovator's solution: creating and sustaining successful growth. Harvard Business School Press, Boston 
Coates A (1987) The commerce in rubber: the first 250 years. Oxford University Press, New York

ETC Group (2005). The potential impacts of nano-scale technologies on commodity markets: the implications for commodity dependent developing countries. Trade-related agenda, development and equity, south centre

ETC Group (2007) Extreme genetic engineering: an introduction to synthetic biology

ETC Group (2008) Commodifying nature's last straw? extreme genetic engineering and the post-petroleum sugar economy

Headrick DR (1996) Botany, chemistry, and tropical development. J World Hist 7(1):1-20

Herbert V, Bisio A (1985) Synthetic rubber: a project that had to succeed. Greenwood Press, Westport

Hounshell DA, Chandler AD (1984) From the American system to mass production, 1800-1932: the development of manufacturing technology in the United States. Johns Hopkins University Press, Baltimore

Kumar P (2001) Scientific experiments in British India: scientists, indigo planters and the state, 1890-1930. Indian Econ Soc Hist Rev 38(3):249-270

Lehrman S (1992) Splicing genes, slicing exports? US firms' bioengineered tropical plants may threaten third world farmers. The Washington Post, Washington

Lim D (1973) Economic growth and development in West Malaysia, 1947-1970 Kuala Lumpur. Oxford University Press, New York

Martin-Leake H (1975) An historical memoir of the indigo industry of Bihar. Econ Bot 29(4):361-371

McCray L, Yeddanapudi N et al (2008) Responses by non-government organizations to concerns about emerging biotechnologies c 1977-2008. Synthetic biology 4.0, Hong Kong University of Science and Technology

McHale TR (1964) Changing technology and shifts in the supply and demand for rubber: an analytical history. Malay Econ Rev IX(2):24-48

McHale TR (1965) Natural rubber and Malaysian economic development. Malay Econ Rev X(1):16-43

Mukunda G (2010) We cannot go on: disruptive innovation and the first world war royal navy. Security Studies (forthcoming)

Mukunda G, Mohr S (2007) DNA Synthesis, synthetic biology, and biosecurity. Synthetic biology 3.0. Zurich, Switzerland
Mukunda G, Oye K et al (2009) What rough beast: synthetic biology, uncertainty, and the future of biosecurity. Massachusetts Institute of Technology Program on Emerging Technologies, Cambridge

Olson M (1971) The logic of collective action: public goods and the theory of groups. Harvard University Press, Cambridge

Oye KA (1992) Economic discrimination and political exchange: world political economy in the 1930s and 1980s. Princeton University Press, Princeton, NJ

Polanyi K (2001) The great transformation: the political and economic origins of our time. Beacon Press, Boston

Rajagopal D, Zilberman D (2007) Review of environmental, economic and policy aspects of biofuels. SSRN eLibrary

Rodrik D (2007) One economics, many recipes: globalization, institutions, and economic growth. Princeton University Press, Princeton and Oxford

Roland G (2000) Transition and economics. MIT Press, Cambridge

Rudner M (1981) Development policies and patterns of Agrarian dominance in the Malaysian rubber export industry. Mod Asian Stud 15(1):83-105

Smith MR, Chandler AD (1977) Harpers ferry armory and the new technology: the challenge of change. Cornell University Press, Ithaca

Swank D (2002) Global capital, political institutions, and policy change in developed welfare states. Cambridge University Press, Cambridge

Synthetic Biology 4.0 Panelists (2008) Investment in synthetic biology: an open discussion between a panel of representatives from the scientific and investment communities. Synthetic Biology 4.0, Hong Kong University of Science and Technology

The World Bank (2009, June 8) Food crisis. Retrieved June 11, 2009, from http://www.worldbank.org/html/extdr/foodprices/

Union of Concerned Scientists (2007, Dec 7) The truth about ethanol. Retrieved May 14, 2009, from http://www.ucsusa.org/ clean_vehicles/technologies_and_fuels/biofuels/the-truth-aboutethanol.html

Vig NJ, Faure M (2004) Green giants?: environmental policies of the United States and the European Union. MIT Press, Cambridge

Wellhausen R (2008) Interviews with NGOs at Synthetic Biology 4.0. $\mathrm{R}$ Wellhausen and G Mukunda. Hong Kong 